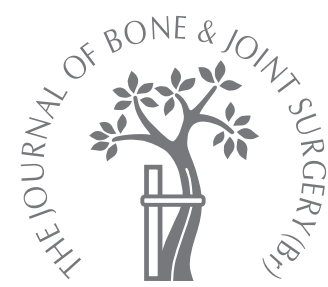

\title{
Heterotopic ossification after the use of commercially available recombinant human bone morphogenetic proteins in four patients
}

\author{
T. W. Axelrad, \\ B. Steen, \\ D. W. Lowenberg, \\ W. R. Creevy, \\ T. A. Einhorn
}

From Boston

University Medical

Center, Boston, USA

- T. W. Axelrad, MD, PhD, Resident Orthopaedic Surgeon B. Steen, MD, Resident Orthopaedic Surgeon W. R. Creevy, MD, Professor Boston University Medical Center, 850 Harrison Avenue, Dowling 2 North, Boston, Massachusetts 02118, USA

D. W. Lowenberg, MD Professor

Department of Orthopaedic Surgery

California Pacific Medica Center, 2100 Webster Street Suite 117, San Francisco 94115, USA

T. A. Einhorn, MD, Professor Department of Orthopaedic Surgery

Boston University Medical

Center, Doctors Office Building, Suite 808,720 Harrison Avenue, Boston, Massachusetts 02118 , USA.

Correspondence should be sent to Professor T. A. Einhorn; e-mail:

Thomas.Einhorn@bmc.org

(C)2008 British Editorial Society of Bone and Joint Surgery doi:10.1302/0301-620X.90B12. $20975 \$ 2.00$

$J$ Bone Joint Surg $[\mathrm{Br}]$ 2008;90-B:1617-22 Received 27 February 2008; Accepted after revision 21 August 2008

\author{
Heterotopic ossification occurring after the use of commercially available bone \\ morphogenetic proteins has not been widely reported. We describe four cases of \\ heterotopic ossification in patients treated with either recombinant bone morphogenetic \\ protein 2 or recombinant bone morphogenetic protein 7 . We found that while some patients \\ were asymptomatic, heterotopic ossification which had occurred around a joint often \\ required operative excision with good results.
}

Recombinant bone morphogenetic proteins (rhBMPs) are present in two commercially available osteo-inductive composite materials currently available for use in the management of the healing of fractures. Infuse (Medtronic Sofamor Danek Inc., Minneapolis, Minnesota) is rhBMP-2 and is used in the treatment of acute open tibial fractures as well as in anterior single-level lumbar vertebral-body spinal fusion, osteogenic protein 1 (OP-1) (Stryker Biotech, Hopkinton, Massachusetts) is rhBMP7 and has shown efficacy in the treatment of recalcitrant nonunions of long bones, ${ }^{1-4}$ posterior lumbar fusion, ${ }^{5}$ and, more recently, in the healing of nonunion of the pelvis. ${ }^{6}$ The potential benefits of using these rhBMPs include a decrease in post-operative pain and donor-site morbidity associated with the harvesting of autografts and a reduction of costs associated with the treatment of delayed and nonunion. In a large prospective, randomised trial, Govender et $\mathrm{al}^{7}$ used rhBMP-2 for the treatment of open tibial fractures. They noted accelerated repair of the fracture and a reduction in infection in type-III open fractures ${ }^{8}$ without an increase in complications when compared with treatment by placebo. These benefits were confirmed in a later report which included an additional 60 patients. ${ }^{9}$ Others have also shown benefits in patients with no reported adverse effects. ${ }^{1,3}$

The use of rhBMPs to augment bone formation has been described in applications including the healing of nonunion, distraction osteogenesis, osteotomy, peri-prosthetic reconstruction, free fibular grafting and joint arthrodesis. ${ }^{2,10-13}$ A theoretical inherent risk with their use is the formation of ectopic bone due to diffusion into adjacent soft tissues. These recombinant proteins have been in clinical use for approximately five years and as yet only a few adverse effects have been described in the literature, these include post-operative swelling in the cervical spine ${ }^{14}$ and heterotopic ossification $(\mathrm{HO})$ of the triceps. ${ }^{15}$ We report the occurrence of substantial HO after the use of Infuse and OP-1 in the treatment of acute fractures and delayed union in four patients.

\section{Case reports}

Details of the four patients are given in Table I. Case 1. A 54-year-old obese woman who fell 25 feet without loss of consciousness sustained an LC2 pelvic fracture according to Gustillo and Anderson, ${ }^{8}$ a comminuted sacral fracture, a grade-II, open supracondylar fracture of the left humerus (Fig. 1a), bilateral pulmonary contusions and a left-sided pneumothorax. She was haemodynamically stabilised and a leftsided chest drain was inserted, she was intubated, sedated and transferred to the operating theatre where the left elbow wound was debrided and a spanning external fixator was applied for initial stabilisation of the fracture. She was returned to the operating theatre 11 days later for closed reduction and percutaneous fixation of the sacral fracture. On the $22 \mathrm{nd}$ day after the injury definitive internal fixation of the distal humeral fracture was undertaken. The elbow was approached posteriorly for fixation of the medial and lateral columns. After reduction, a gap, which remained medially was filled with fresh autograft consisting of fracture callus and new bone initially debrided from the site of the fracture. Although the risk of nonunion in distal humeral fractures is 
Table I. Comparison of the four cases with regard to the type of injury, commercial bone morphogenetic protein (BMP) used, and the extent of heterotopic ossification (HO)

\begin{tabular}{|c|c|c|c|c|c|c|c|c|c|}
\hline \multirow[b]{2}{*}{ Case } & \multicolumn{7}{|l|}{ Injury type } & \multicolumn{2}{|c|}{ Soft-tissue involvement } \\
\hline & Location & AO classification & Open/grade & Reason for use & $\begin{array}{l}\text { BMP type } \\
\text { used }\end{array}$ & $\begin{array}{l}\text { Thrombin } \\
\text { pouch }\end{array}$ & $\begin{array}{l}\text { Brooker classification } \\
\text { of } \mathrm{HO}\end{array}$ & Fascial plane & Muscle \\
\hline 1 & Distal humerus & $\mathrm{C} 2$ & Yes/II & Bone loss & Infuse & No & IV & Yes & Yes \\
\hline 2 & Humeral shaft & $\mathrm{A} 1$ & No & Nonunion & OP-1 & Yes & III & Yes & Yes \\
\hline 3 & Humeral shaft & $\mathrm{A} 1$ & No & Nonunion & OP-1 & Yes & IV & Yes & Yes \\
\hline 4 & Distal humerus & $\mathrm{C} 2$ & No & Bone loss & OP-1 & Yes & III & Yes & Yes \\
\hline
\end{tabular}

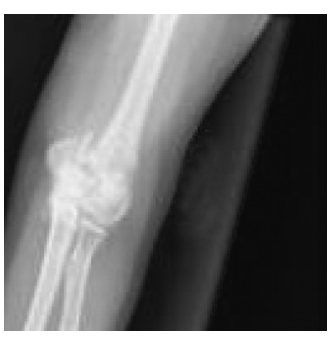

Fig. 1a

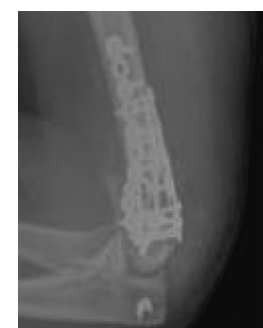

Fig. 1b

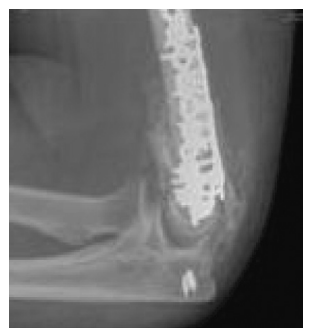

Fig. 1c

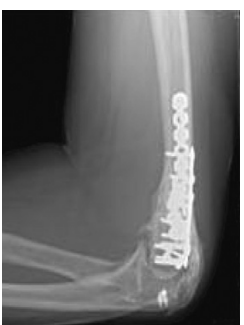

Fig. 1d

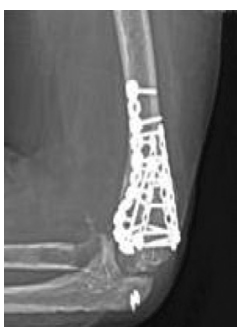

Fig. 1e

Radiographs of a 54-year-old woman with multiple injuries, including a grade-II open supracondylar fracture of the left humerus showing a) the initial injury, b) after fixation and treatment by autograft supplemented with BMP-2, c) at ten weeks after operation with evidence of heterotopic ossification, d) heterotopic ossification bridging the elbow posteriorly and extending into the fascial planes five months after injury and e) after excision of heterotopic ossification with stable reduction of the elbow.

thought to be low ${ }^{16}$ the loss of bone, the open nature of the injury, and the multiple surgical procedures may have placed her at a higher risk of nonunion. Therefore the graft was augmented with Infuse BMP-2 on an absorbable collagen sponge placed along the anteromedial, anterolateral and direct anterior borders of the distal humerus. Postoperative rehabilitation included serial static splinting which gradually increased the degree of extension. At seven weeks radiographs showed adequate formation of callus and maintenance of reduction (Fig. 1b), with some $\mathrm{HO}$ predominantly posteriorly (Fig. 1c). At five months after injury, she presented with an acute decrease in range of movement and with the elbow fixed at $90^{\circ}$. Radiographs showed bridging $\mathrm{HO}$ from the olecranon to the distal humerus which extended posteriorly into the fascial planes (Fig. 1d). She underwent excision of $\mathrm{HO}$ with capsular release and manipulation under anaesthesia. After anterior and posterior debridement and capsulorrhaphy, she regained full flexion and loss of $5^{\circ}$ of extension, but at three weeks after operation was found to have medial dislocation of the ulna and radius. Subsequently, she underwent open reduction with placement of a transfixion screw through the olecranon into the distal humerus. After four weeks, the transfixion screw was removed and the passive range of movement was from $30^{\circ}$ to $120^{\circ}$. At the most recent follow-up (6 months), the range of movement had decreased to $30^{\circ}$ to $100^{\circ}$. Radiographs showed no recurrent $\mathrm{HO}$ and stable reduction of the elbow (Fig. 1e).
Case 2. A 55-year-old man sustained a fracture of the left humeral shaft with no other significant injuries. Initial fixation of the fracture was undertaken with a locked intramedullary nail. Radiographs at 16 months showed a nonunion (Fig. 2a) and he underwent removal of the intramedullary nail, debridement of the nonunion and lateral plating of the humerus with placement of an OP-1/ thrombin pouch. This consisted of placing OP-1 at the site of the fracture followed by adding thrombin slowly over several minutes to augment healing (Fig. 2b). Healing progressed with resolution of pain but at ten weeks after operation he complained of discomfort and swelling of the arm. Radiographs showed $\mathrm{HO}$ of the soft tissues lateral to the plate. At two years the lesion was shown to be stable and he was asymptomatic. At 26 months after revision plating (Fig. 2c), he underwent hemiarthroplasty of the ipsilateral shoulder for worsening shoulder pain and degenerative joint disease. The upper aspect of the $\mathrm{HO}$ was resected to allow removal of the proximal screw and placement of the prosthesis. Since this time he has been free from symptoms.

Case 3. A 61-year-old woman with multiple medical problems including coronary artery disease sustained a fracture of the right humeral shaft in a fall. The fracture was initially treated with an intramedullary nail. One year later there was nonunion and fixation was augmented by synthetic demineralised bone matrix, this was done at an outside facility. 


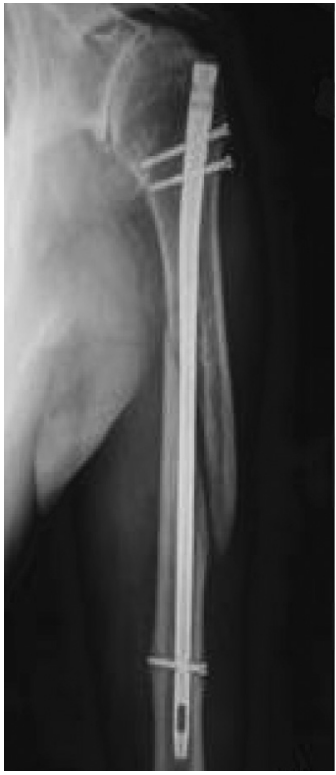

Fig. $2 a$

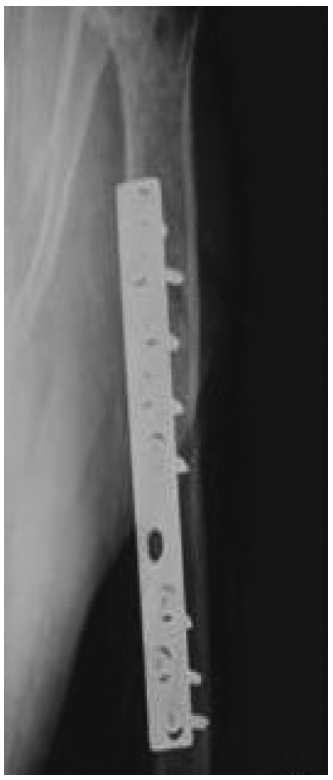

Fig. $2 b$

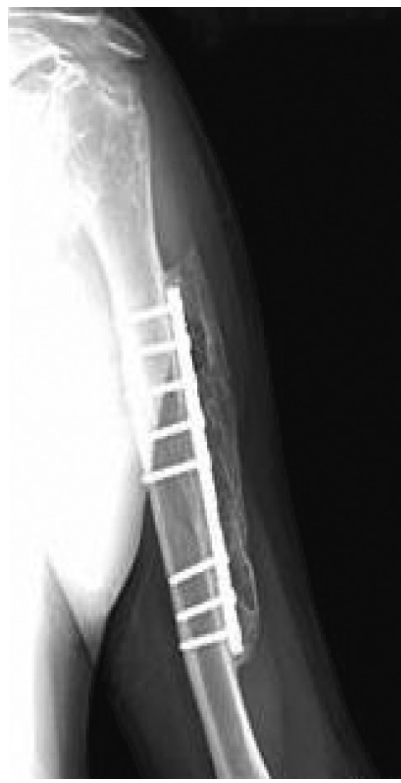

Fig. 2c

Radiograph of a 55-year-old man who underwent fixation of a fracture of the left humerus with a locked intramedullary nail showing a) atrophic nonunion 16 months after injury, b) following further fixation with a plate and the addition of OP-1 and c) stable heterotopic ossification 26 months later.

Two years after the injury (Fig. 3a), there remained a symptomatic nonunion. The nail was removed and double plating of the humeral shaft was carried out, augmented by an OP-1/ thrombin pouch. At six weeks after the operation she complained of pain and acute limitation of movement from $70^{\circ}$ to $90^{\circ}$. Radiographs showed massive diffuse formation of $\mathrm{HO}$ from the surgical neck of the humerus extending down to the anterior aspect of the elbow along the course of brachialis (Fig. $3 b)$. She underwent exploration and excision of the calcified brachialis which was found to be the cause of the restricted movement. The radiological appearance of the new bone was diffuse in nature and lacked the sharp borders seen in the more prevalent types of $\mathrm{HO}$ which form as a result of enchondral ossification. ${ }^{17}$ The images were more characteristic of intramembranous bone function, similar to that seen in progressive osseous heteroplasia, ${ }^{18-20}$ although no histological examination was undertaken to confirm this observation. At follow-up at one year she remained asymptomatic with a full range of movement.

Case 4. A 20-year-old woman sustained a grade-II open, ${ }^{8} \mathrm{AO}$ type C-2 fracture ${ }^{21}$ of the distal humerus which was initially treated by irrigation, debridement, primary closure, and application of a cast. Radiographs, one week later, showed some intra-articular displacement (Figs $4 \mathrm{a}$ and $4 \mathrm{~b}$ ) and open reduction and internal fixation was performed (Fig. 4c). The site of the fracture was irrigated before and after fixation and an OP$1 /$ thrombin pouch was placed adjacent to the area of comminution. At follow-up at two months there was limited movement, from $35^{\circ}$ to $100^{\circ}$. Radiographs showed some ectopic ossification anterior to the trochlea and posteriorly at the tip of the olecranon (Fig. 4d). He returned at 18 months with pain

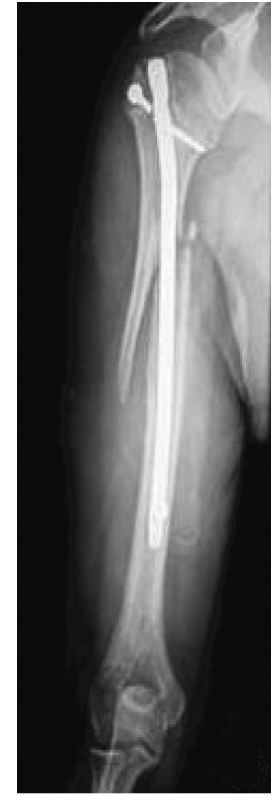

Fig. 3a

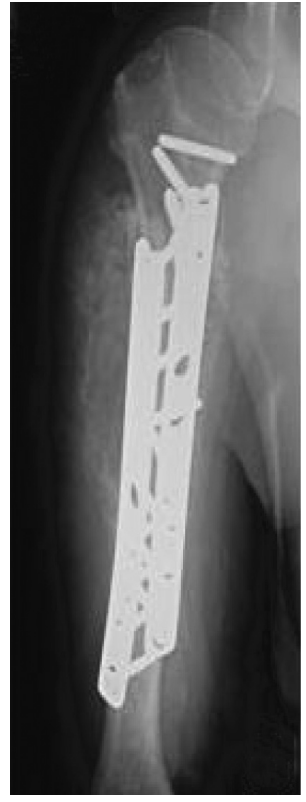

Fig. $3 b$
Radiographs of a 61-year-old woman with a fracture of the right humerus which had been treated by an intramedullary nail showing a) nonunion at two years which was treated by double plating and OP-1, and b) massive formation of heterotopic ossification.

and limitation of movement and there was a mature area of $\mathrm{HO}$ anteriorly and posteriorly, incongruent with the olecranon (Fig. 4e). She underwent excision of the posterior $\mathrm{HO}$ with improvement in the range of movement and relief from pain. 


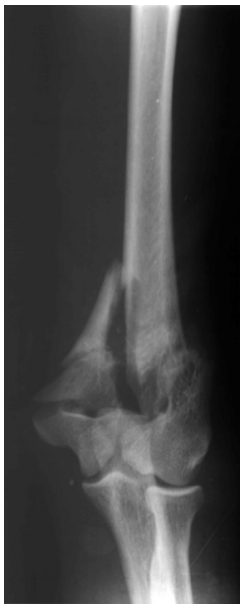

Fig. $4 a$

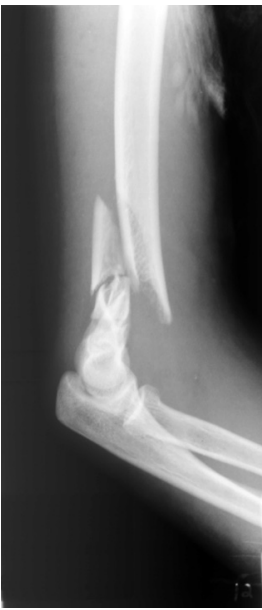

Fig. 4b

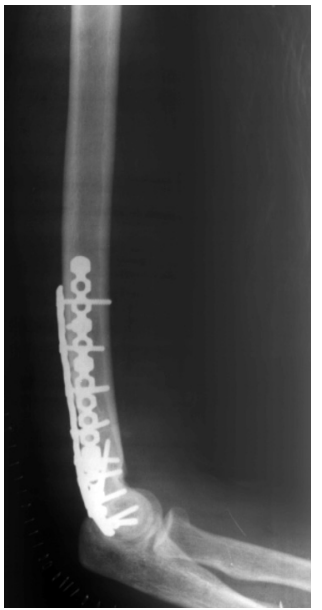

Fig. 4c

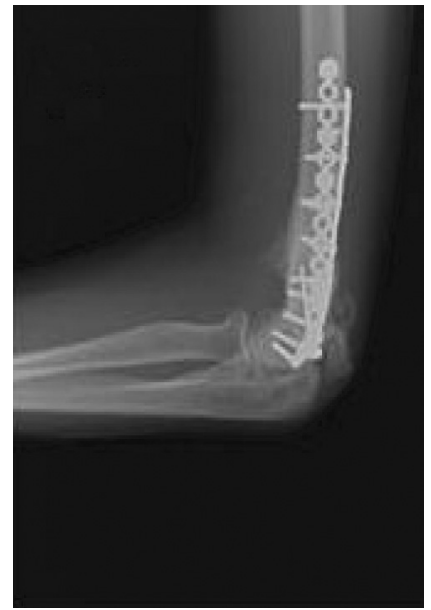

Fig. 4d

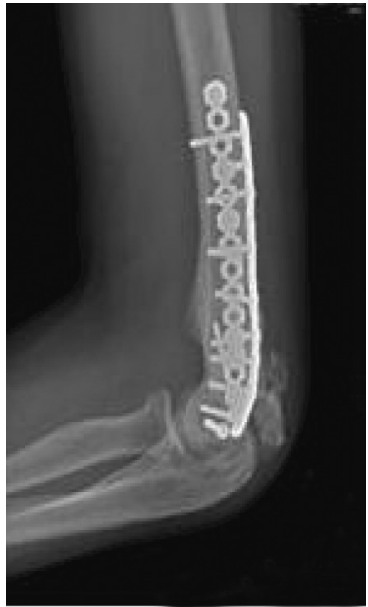

Fig. 4 e

Radiographs of a 20-year-old woman showing a and b) a grade-II open, AO type-C-2 fracture of the distal humerus, c) fixation by a combination of lateral and medial column plating and multiple lag screws with OP-1 supplementation, d) early heterotopic ossification anterior to the trochlea and posteriorly at the tip of the olecranon and e) persistence of mature heterotopic ossification anteriorly and posteriorly.

\section{Discussion}

$\mathrm{HO}$ can occur in many sites. ${ }^{22-27}$ While the mechanisms associated with many cases of $\mathrm{HO}$ remain elusive, one hypothesis is that it is associated with an inflammatory response resulting from the elaboration of specific biochemical mediators and growth factors, which leads to the recruitment of mesenchymal stem cells capable of differentiating into cartilage and/or bones. ${ }^{28,29}$ The role of an inflammatory response as a contributing factor in the development of $\mathrm{HO}$ can be inferred from the apparent prophylactic effects of indometacin in the prevention of $\mathrm{HO}$ around the pelvis after hip surgery, acetabular fracture, ${ }^{30-32}$ and in the spine after injury to the spinal cord. ${ }^{33}$ Other anti-inflammatory agents have also been shown to be effective in the prevention of $\mathrm{HO}$ after hip replacement. ${ }^{34}$ Some authors have, however, recently questioned the use of indometacin as prophylaxis after acetabular fractures. ${ }^{35}$

There are several trauma-related situations in which $\mathrm{HO}$ is known to occur. Myositis ossificans can develop secondary to an intramuscular haematoma. The bone typically forms through endochondral ossification. ${ }^{19}$ This begins with inflammation and includes oedema and cellular infiltration. As formation progresses, proliferation of fibroblasts and deposition of osteoid occur. The rim is preferentially ossified and is replaced by lamellar bone as the HO reaches maturation. ${ }^{36}$ Pelvic fractures which are treated through a posterior approach are also subject to high rates of $\mathrm{HO}^{37}$ It is possible that systemic factors play a role in these situations, possibly related to genetic predisposition based on human leukocyte antigens. ${ }^{38,39}$ Susceptible patients may express or release factors which can initiate the formation of new bone at these sites. Patients with cerebral trauma are susceptible to $\mathrm{HO}$, and systemic levels of basic fibroblast growth factor have been shown to be elevated in these instances. ${ }^{40}$ Eid et $\mathrm{al}^{41}$ found that serum from polytraumatised patients significantly inhibited apoptosis in human mesenchymal bone-marrow cells, further implicating a systemic factor in the enhancement of $\mathrm{HO}$.

HO of the elbow may occur after burns and dislocation ${ }^{42,43}$ but is uncommon after operative management of intra-articular fracture of the distal humerus. ${ }^{44}$ The rate of $\mathrm{HO}$ after injury to the elbow has been reported to be between $0 \%$ and $14 \%$, but these studies included cases of dislocation and head injury, ${ }^{45-47}$ neither of which occurred in any of our patients. In a review of intra-articular distal humeral fractures over a period of five years, Helfet and Schmeling ${ }^{48}$ found an incidence of only $4 \%$ for all degrees of HO. The formation of $\mathrm{HO}$ in our cases was related to the force of the injury and specifically to fracture dislocations.

The degree of soft-tissue injury has been correlated with the formation of $\mathrm{HO}$ in distal humeral fractures ${ }^{48}$ and may have played a role in the patient treated with BMP-2 in our series. Kundel et $\mathrm{al}^{49}$ noted that $\mathrm{HO}$ usually occurred anteriorly. The diffuse nature of the new bone formation, particularly on the posterior aspect of the elbow (cases 1 and 4), also suggests an effect of growth-factor supplementation.

As previously stated, inflammation associated with the bone and soft-tissue trauma may have provided the chemotactic stimulus for the recruitment of the necessary mesenchymal precursor cells. It has been proposed that BMP4 is involved in the extensive endochondral ossification seen in fibrodysplasia ossificans progressiva. ${ }^{19}$ The transfer of the gene for BMP2 into skeletal muscle has been shown to promote both endochondral and intramembranous ossification. ${ }^{50}$ Expression of BMP2 and BMP7 have also been shown to induce BMP4 expression. ${ }^{51}$ The addition of rhBMPs may then have provided the osteoinductive stimulus for chondro-osteogenic differentiation leading to the development of $\mathrm{HO}$ in these cases. 
Until now there has been only one published report of $\mathrm{HO}$ and the use of rhBMPs in treatment of fractures. Wysocki and Cohen ${ }^{15}$ described $\mathrm{HO}$ in a fracture at the elbow treated with OP-1. The patient had nonunion of the distal humerus and a history of smoking which may have had a contributing role, although the intramuscular location of the new bone formation was not typical.

There have been at least two reports of complications from the use of Infuse in the cervical spine. ${ }^{14,52}$ Shields et $\mathrm{al}^{14}$ published a retrospective review of 151 patients who had undergone anterior cervical fusion supplemented by high doses (up to $2.1 \mathrm{mg}$ per level) of Infuse.

Complications were reported in $23.2 \%$ of patients and included $15(9.9 \%)$ haematomas and two cases of paralysis of the vocal cords and Horner Syndrome, but these findings were not by reported Smucker et al. ${ }^{52}$ However, the latter found a high rate of anterior cervical swelling with the use of rhBMP2. Although the pathogenetic mechanisms associated with these complications may be distinct from those related to the development of $\mathrm{HO}$ in our patients, their occurrence underlines the importance of careful short- and long-term follow-up of patients treated with new pharmaceutical and biological materials.

HO can result in substantial morbidity, particularly when it occurs around a joint, which in our series required additional surgery. Our cases suggest the possibility of a cause-and-effect relationship between the development of $\mathrm{HO}$ and the use of rhBMP in skeletal reconstruction. In order to test this hypothesis, a sufficiently powered prospective clinical study is required.

No benefits in any form have been received or will be received from a commer cial party related directly or indirectly to the subject of this article.

\section{References}

1. Dimitriou R, Dahabreh Z, Katsoulis E, et al. Application of recombinant BMP-7 on persistent upper and lower limb non-unions. Injury 2005;36(Suppl 4):51-9.

2. Giannoudis PV, Tziopis C. Clinical applications of BMP-7: the UK perspective. Injury 2005;36(Suppl 3):47-50

3. Friedlaender GE, Perry CR, Cole JD, et al. Osteogenic protein-1 (bone morphogenetic protein-7) in the treatment of tibial nonunions. J Bone Joint Surg [Am]2001;83A(Suppl 1):151-8.

4. Burkhart KJ, Rommens PM. Intramedullary application of bone morphogenetic protein in the management of a major bone defect after an llizarov procedure. J Bone Joint Surg [Br] 2008;90-B:806-9.

5. Vaccaro AR, Whang PG, Patel T, et al. The safety and efficacy of OP-1 (rhBMP-7) as a replacement for iliac crest autograft for posterolateral lumbar arthrodesis: minimum 4-year follow-up of a pilot study. Spine J 2007;8:457-65.

6. Giannoudis PV, Psarakis S, Kanakaris NK, Pape HC. Biological enhancement of bone healing with bone morphogenetic protein-7 at the clinical setting of pelvic girdle non-unions. Injury 2007;38(Suppl 4):43-8.

7. Govender S, Csimma C, Genant HK, et al. Recombinant human bone morphogenetic protein-2 for treatment of open tibial fractures: a prospective, controlled, randomized study of four hundred and fifty patients. J Bone Joint Surg [Am] 2002;84A:2123-34

8. Gustillo RB, Anderson JT. Prevention of infection in the treatment of one thousand and twenty-five open fractures of long bones: retrospective and prospective analyses. J Bone Joint Surg [Am] 1976;58-A:453-8.

9. Swiontkowski MF, Aro HT, Donell S, et al. Recombinant human bone morphogenetic protein-2 in open tibial fractures: a subgroup analysis of data combined from two prospective randomized studies. J Bone Joint Surg [Am] 2006;88-A:1258-65.
10. Axelrad TW, Kakar S, Einhorn TA. New technologies for the enhancement of skeletal repair. Injury 2007;38(Suppl 1):49-62.

11. Giannoudis PV, Dinopoulos H, Tsiridis E. Bone substitutes: an update. Injury 2005;36(Suppl 3):20-7.

12. Jensen TB, Overgaard $\mathbf{S}$, Lind $\mathbf{M}$, et al. Osteogenic protein-1 increases the fixation of implants grafted with morcellised bone allograft and Pro0stean bone substitute: an experimental study in dogs. J Bone Joint Surg [Br] 2007;89-B:121-6.

13. Watanabe K, Tsuchiya H, Sakurakichi K, Tomita K. Bone transport using hydroxyapatite loaded with bone morphogenetic proteins in rabbits. J Bone Joint Surg [Br] 2007;89-B:1122-9.

14. Shields LB, Raque GH, Glassman SD, et al. Adverse effects associated with highdose recombinant human bone morphogenetic protein-2 use in anterior cervical spine fusion. Spine 2006;31:542-7.

15. Wysocki RW, Cohen MS. Ectopic ossification of the triceps muscle after application of bone morphogenetic protein-7 to the distal humerus for recalcitrant nonunion: a case report. J Hand Surg [Am] 2007;32:647-50.

16. Helfet DL, Kloen P, Anand N, Rosen HS. Open reduction and internal fixation of delayed unions and nonunions of fractures of the distal part of the humerus. $J$ Bone Joint Surg [Am] 2003;85-A:33-40.

17. Kransdorf MJ, Meis JM, Jelinek JS. Myositis ossificans: MR appearance with radiologic-pathologic correlation. AJR Am J Roentgenol 1991;157:1243-8.

18. Kumagai K, Motomura K. Egashira M, et al. A case of progressive osseous heteroplasia: a first case in Japan. Skeletal Radio/ 2008;37:563-7.

19. Kaplan FS, Glaser DL, Hebela N, Shore EM. Heterotopic ossification. J Am Acad Orthop Surg 2004;12:116-25.

20. Schmidt AH, VIncent KA, Aiona MD. Hemimelic progressive osseous heteroplasia: a case report. J Bone Joint Surg [Am] 1994;76-A:907-12

21. Wainwright AM, Williams JR, Carr AJ. Interobserver and intraobserver variation in classification systems for fractures of the distal humerus. J Bone Joint Surg [Br] 2000;82-B:636-42

22. Ahrengart L. Periarticular heterotopic ossification after total hip arthroplasty: risk factors and consequences. Clin Orthop 1991;263:49-58.

23. Chan ED, Morales DV, Welsh CH, McDermott MT, Schwarz MI. Calcium deposition with or without bone formation in the lung. Am J Respir Crit Care Med 2002:165:1654-69.

24. Lai HJ, Jao SW, Lee TY, Ou JJ, Kang JC. Heterotopic mesenteric ossification after total colectomy for bleeding diverticulosis of the colon: a rare case report. J Formos Med Assoc 2007;106(2 Suppl):32-6.

25. Mohler ER 3rd, Gannon F, Reynolds C, et al. Bone formation and inflammation in cardiac valves. Circulation 2001;103:1522-8.

26. Tanaka H, Nagai E, Murata H, et al. Involvement of bone morphogenetic protein2 (BMP-2) in the pathological ossification process of the spinal ligament. Rheumato/ogy (Oxford) 2001;40:1163-8.

27. Toyran S, Lin AY, Edward DP. Expression of growth differentiation factor-5 and bone morphogenetic protein-7 in intraocular osseous metaplasia. $\mathrm{Br} \mathrm{J}$ Opthalmol 2005;89:885-90

28. Cowan CM, Jiang $\mathbf{X}$, Hsu T, et al. Synergistic effects of Nell-1 and BMP-2 on the osteogenic differentiation of myoblasts. J Bone Miner Res 2007;22:918-30.

29. Kaplan FS, Glaser DL, Shore EM, et al. Hematopoietic stem-cell contribution to ectopic skeletogenesis. J Bone Joint Surg [Am] 2007;89-A:347-57.

30. Karunakar MA, Sen A, Bosse MJ, et al. Indometacin as prophylaxis for heterotopic ossification after the operative treatment of fractures of the acetabulum. J Bone Joint Surg [Br] 2006;88-B:1613-17

31. Knelles D, Barthel T, Karrer A, et al. Prevention of heterotopic ossification after total hip replacement: a prospective, randomised study using acetylsalicyclic acid, indomethacin and fractionale or single-dose irradiation. J Bone Joint Surg $[\mathrm{Br}]$ 1997;79-B:596-602.

32. Board TN, Karva A, Board RE, Gambhir , Porter ML. The prophylaxis and treatment of heterotopic ossification following lower limb arthroplasty. J Bone Joint Surg [Br] 2007;89-B:434-40.

33. Estrores IM, Harrington A, Banovac K. C-reactive protein and erythrocyte sedimentation rate in patients with heterotopic ossification after spinal cord injury. J Spinal Cord Med 2004;27:434-7.

34. Saudan M, Saudan P, Perneger T, et al. Celecoxib versus ibuprofen in the prevention of heterotopic ossification following total hip replacement: a prospective randomised trial. J Bone Joint Surg [Br] 2007;89-B:155-9.

35. Karunakar MA, Sen A, Bosse MJ, et al. Indometacin as prophylaxis for heterotopic ossification after the operative treatment of fractures of the acetabulum. J Bone Joint Surg [Br]2006;88-B:1613-17.

36. Shehab D, Elgazzar AH, Collier BD. Heterotopic ossification. J Nucl Med 2002:43:346-53. 
37. Yu JK, Chiu FY, Feng CK, Chung TY, Chen TH. Surgical treatment of displaced fractures of posterior column and posterior wall of the acetabulum. Injury 2004;35:766-70

38. Larson JM, Michalski JP, Collacott EA, et al. Increased prevalence of HLA-B27 in patients with ectopic ossification following traumatic spinal cord injury. Rheumatol Rehabil 1981;20:193-7

39. Garland DE, Alday B, Venos KG. Heterotopic ossification and HLA antigens. Arch Phys Med Rehabil 1984;65:531-2.

40. Wildburger R, Zarkovic N, Egger G, et al. Comparison of the values of basic fibroblast growth factor determined by an immunoassay in the sera of patients with traumatic brain injury and enhanced osteogenesis and the effects of the same sera on the fibroblast growth in vitro. Eur J Clin Chem Clin Biochem 1995;33:693-8.

41. Eid K, Labler L, Ertel W, Trentz O, Keel M. Systemic effects of severe trauma on the function and apoptosis of human skeletal cells. J Bone Joint Surg [Br] 2006;88B:1394-400

42. Ring D, Jupiter JB. Operative release of complete ankylosis of the elbow due to heterotopic bone in patients without severe injury of the central nervous system. J Bone Joint Surg [Am] 2003;85-A:849-57.

43. Tsionos I, Leclercq C, Rochet JM. Heterotopic ossification of the elbow in patients with burns: results after early excision. J Bone Joint Surg [Br] 2004;86-B:396-403.

44. Dornberg JN, van Duijn PJ, Linzel D, et al. Surgical treatment of intra-articular fractures of the distal part of the humerus: functional outcome after twelve to thirty years. J Bone Joint Surg [Am] 2007;89-A:1524-32.
45. McAuliffe JA, Wolfson AH. Early excision of heterotopic ossification about the elbow followed by radiation therapy. J Bone Joint Surg [Am] 1997;79-A:749-55.

46. Garland DE, O'Hollaren RM. Fractures and dislocations about the elbow in the head-injured adult. Clin Orthop 1982;168:38-41.

47. Doornberg JN, van Duijn PJ, Linzel D, et al. Surgical treatment of intra-articular fractures of the distal part of the humerus: functional outcome after twelve to thirty years. J Bone Joint Surg [Am] 2007;89-A:1524-32

48. Helfet DL, Schmeling GJ. Bicondylar intraarticular fractures of the distal humerus in adults. Clin Orthop 1993;292:26-36.

49. Kundel K, Braun W, Wieberneit J, Ruter A. Intraarticular distal humerus frac tures: factors affecting functional outcome. Clin Orthop 1996;332:200-8.

50. Kawai M, Bessho K, Maruyama H, Miyazaki J, Yamamoto T. Human BMP-2 gene transfer using transcutaneous in vivo electroporation induced both intramembranous and endochondral ossification. Anat Rec A Discov Mol Cell Evol Biol 2005;287:1264-71.

51. Kawai M, Bessho K, Maruyama H, Miyazaki J, Yamamoto T. Simultaneous gene transfer of bone morphogenetic protein (BMP)-2 and BMP-7 by in vivo electroporation induces rapid bone formation and BMP-4 expression. BMC Musculoskelet Disord 2006;7:62.

52. Smucker JD, Rhee JM, Singh K, Yoon ST, Heller JG. Increased swelling complications associated with off-label usage of rhBMP-2 in the anterior cervical spine. Spine 2006;31:2813-19 